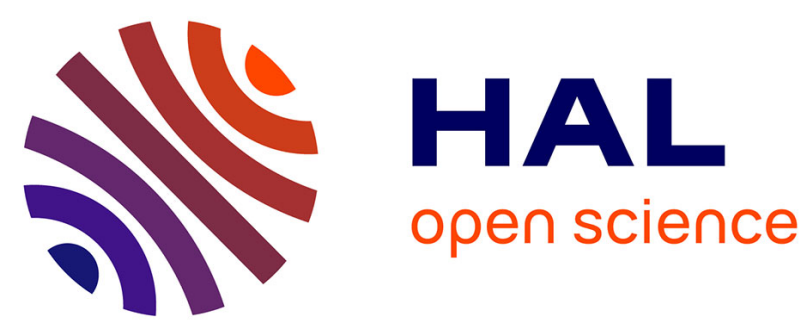

\title{
HRTEM and chemical study of an ion-irradiated chromium/zircaloy-4 interface
}

A. Wu, J. Ribis, J.-C. Brachet, E. Clouet, F. Leprêtre, E. Bordas, Benoît

Arnal

\section{- To cite this version:}

A. Wu, J. Ribis, J.-C. Brachet, E. Clouet, F. Leprêtre, et al.. HRTEM and chemical study of an ion-irradiated chromium/zircaloy-4 interface. Journal of Nuclear Materials, 2018, 504, pp.289-299. 10.1016/j.jnucmat.2018.01.029 . cea-02428719

\section{HAL Id: cea-02428719 https://hal-cea.archives-ouvertes.fr/cea-02428719}

Submitted on 6 Jan 2020

HAL is a multi-disciplinary open access archive for the deposit and dissemination of scientific research documents, whether they are published or not. The documents may come from teaching and research institutions in France or abroad, or from public or private research centers.
L'archive ouverte pluridisciplinaire HAL, est destinée au dépôt et à la diffusion de documents scientifiques de niveau recherche, publiés ou non, émanant des établissements d'enseignement et de recherche français ou étrangers, des laboratoires publics ou privés. 


\title{
HRTEM and chemical study of an ion-irradiated chromium/zircaloy-4 interface
}

\author{
A. Wu ${ }^{\text {a }}$, J. Ribis ${ }^{\text {a, }}{ }^{*}$, J.-C. Brachet ${ }^{\text {a }}$, E. Clouet ${ }^{\text {b }}$, F. Leprêtre ${ }^{\text {b }}$, E. Bordas ${ }^{\text {b }}$, B. Arnal ${ }^{a}$ \\ a CEA, DEN, Service de Recherches Metallurgiques Appliquées, Université Paris-Saclay, F-91191 Gif-sur-Yvette, France \\ b $C E A, D E N$, DMN, Service de Recherches de Metallurgie Physique, Université Paris-Saclay, F-91191 Gif-sur-Yvette, France
}

\section{A R T I C L E I N F O}

\section{Article history:}

Received 20 September 2017

Received in revised form

6 December 2017

Accepted 15 January 2018

Available online 2 February 2018

\section{Keywords:}

High resolution transmission electron

microscopy

Interface

Ion-irradiation

Accident tolerant fuel

\begin{abstract}
A B S T R A C T
Chromium-coated zirconium alloys are being studied as Enhanced Accident Tolerant Fuel Cladding for Light Water Reactors (LWRs). Those materials are especially studied to improve the oxidation resistance of LWRs current fuel claddings in nominal and at High Temperature (HT) for hypothetical accidental conditions such as LOss of Coolant Accident. Beyond their HT behavior, it is essential to assess the materials behavior under irradiation. A first generation chromium/Zircaloy-4 interface was thus irradiated with $20 \mathrm{MeV} \mathrm{Kr}^{8+}$ ions at $400^{\circ} \mathrm{C}$ up to $10 \mathrm{dpa}$. High-Resolution Transmission Electron Microscopy and chemical analysis (EDS) were conducted at the $\mathrm{Cr} / \mathrm{Zr}$ interface. The atomic structure of the interface reveals the presence of $\mathrm{Zr}(\mathrm{Fe}, \mathrm{Cr})_{2}$ Laves phase, displaying both $\mathrm{C} 14$ and $\mathrm{C} 15$ structure. After irradiation, only the C14 structure was observed and atomic row matching was preserved across the different interfaces, thus ensuring a good adhesion of the coating after irradiation.
\end{abstract}

(c) 2018 Elsevier B.V. All rights reserved.

\section{Contents}

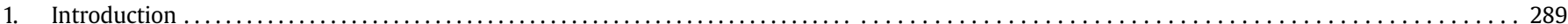

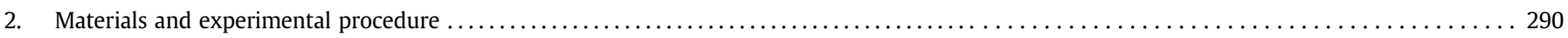

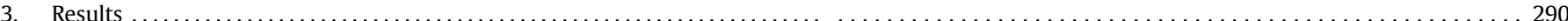

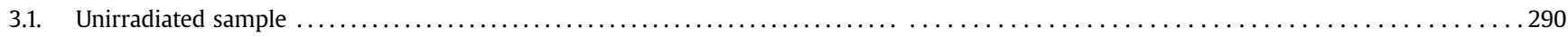

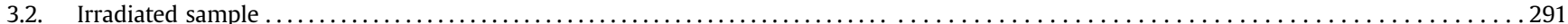

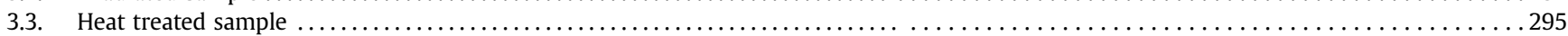

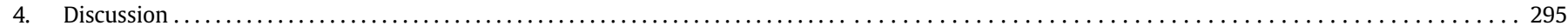

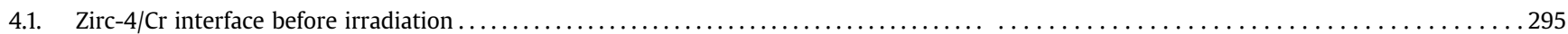

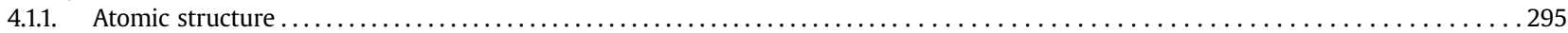

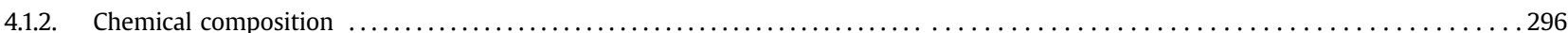

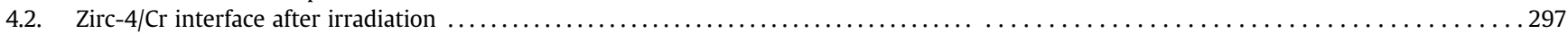

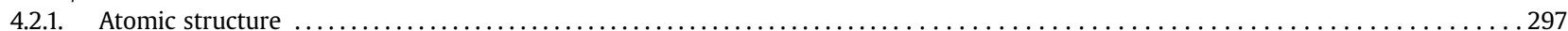

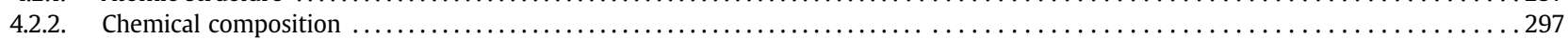

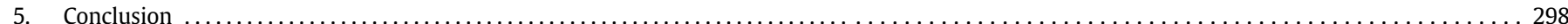

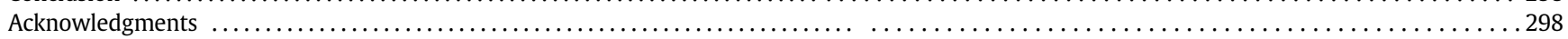

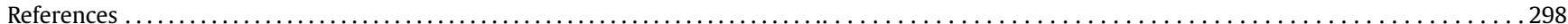

\footnotetext{
* Corresponding author.

E-mail address: joel.ribis@cea.fr (J. Ribis).
}

\section{Introduction}

In order to increase the oxidation resistance of zirconium alloy nuclear fuel claddings both in nominal and accidental conditions such as LOss of Coolant Accident (LOCA), different protective 
coatings are being studied [1-13]. Among the different coatings considered so far, including nitride, MAX phase and metallic ones, chromium coatings showed promising results [14-21]. Studies on unirradiated samples have shown good behavior of these coatings, both in autoclave ( $415^{\circ} \mathrm{C}$, steam, 100 bars) with conditions close to nominal ones and at high temperature oxidation (vapor, up to $1300^{\circ} \mathrm{C}$ ) mimicking accidental conditions [15,16,18,19]. However, if the behavior under steam oxidation at HT is promising, the stability of chromium under irradiation has only been scarcely studied [22-29]. Only few experimental studies assessing the stability under neutron irradiation of some other coatings such as $\mathrm{CrN}$, TiAlN and $\mathrm{AlCrN}$ have been recently initiated [30-32]. These studies have been performed in the experimental HALDEN reactor under PWR/ BWR representative environment. It has been shown that some of the coatings studied (especially those containing aluminium) entirely disappeared after irradiation showing the great interest of studying the $\mathrm{Cr}$ coating/ $\mathrm{Zr}$ interfaces behavior upon irradiation [32]. This paper presents the first HRTEM observations and chemical analysis (EDS) done on chromium/zircaloy-4 interface before and after ion irradiation at $400^{\circ} \mathrm{C}$. A first paper presenting a fine characterization of an unirradiated chromium/zircaloy-4 interface shows a polytyped structured Laves Phases in the vicinity of the interface and a preserved crystallinity throughout the $\mathrm{Zr} / \mathrm{Cr}$ interface [33]. However, in order to compare directly the unirradiated material to the ion irradiated material, this fine characterization is necessary on our sample. That is why, we first present, the chemistry and structure of the as-received material. Then, the chemistry and structure of the ion irradiated material is presented. At last, the irradiated material is compared to a $400^{\circ} \mathrm{C}-7 \mathrm{~h} 45 \mathrm{~min}$ heat treated sample (same time and temperature as the irradiated material) to distinguish the effect of temperature to those of irradiation. The discussion compares the results of the three materials and allows to conclude on the effects of ion irradiations on the $\mathrm{Cr} / \mathrm{Zirc}-4$ interface.

\section{Materials and experimental procedure}

The base material is a low-tin Zircaloy-4 sheet (thickness $1.2 \mathrm{~mm}$ ) coated with chromium by a lab scale PVD process developed and patented by CEA [17]. This material corresponds to first generation chromium coated claddings and thus, the results illustrated here are not fully representative of the last generation of $\mathrm{Cr}$ coated materials currently developed in the framework of CEAEDF-AREVA collaborative program. In order to irradiate the whole coating thickness with accelerated ions, an approximately $2.5 \mu \mathrm{m}$ thick chromium coating has been studied here. The bulk material is irradiated thanks to the Jannus-Saclay Facility [34] using $20 \mathrm{MeV}$ $\mathrm{Kr}^{8+}$ ions. The irradiation temperature was set to $400^{\circ} \mathrm{C}$ and controlled with a thermocouple and a thermal camera. The average ion flux was $2.24 \times 10^{11}$ ions.cm ${ }^{-2} . \mathrm{s}^{-1}$. The damage caused in the material was calculated with the simulation software SRIM 2008 using the Quick Damage Kinchin-Pease mode as recommended by Stoller et al. [35]. The displacement energy for chromium and zirconium is set at $40 \mathrm{eV}$. According to this calculation, the maximum damage is $10 \mathrm{dpa}$ at the chromium/zirconium alloy interface (Fig. 1). Irradiation parameters are summarized in Table 1.

Cross sectional thin foil samples were extracted from the irradiated material and from the as-received reference using FEI Helios Nanolab 650 microscope (Focus Ion Beam using Gallium ions coupled with Scanning Electron Microscope).

High Resolution Transmission Electron Microscopy (HRTEM) observations and chemical analysis of the two samples were performed using $200 \mathrm{keV}$ Transmission Electron Microscope (TEM) JEOL 2010F coupled with Energy Dispersive Spectroscopy (EDS) Inca X Sight Oxford Instrument.

To distinguish the effect of irradiation from the effect of heat

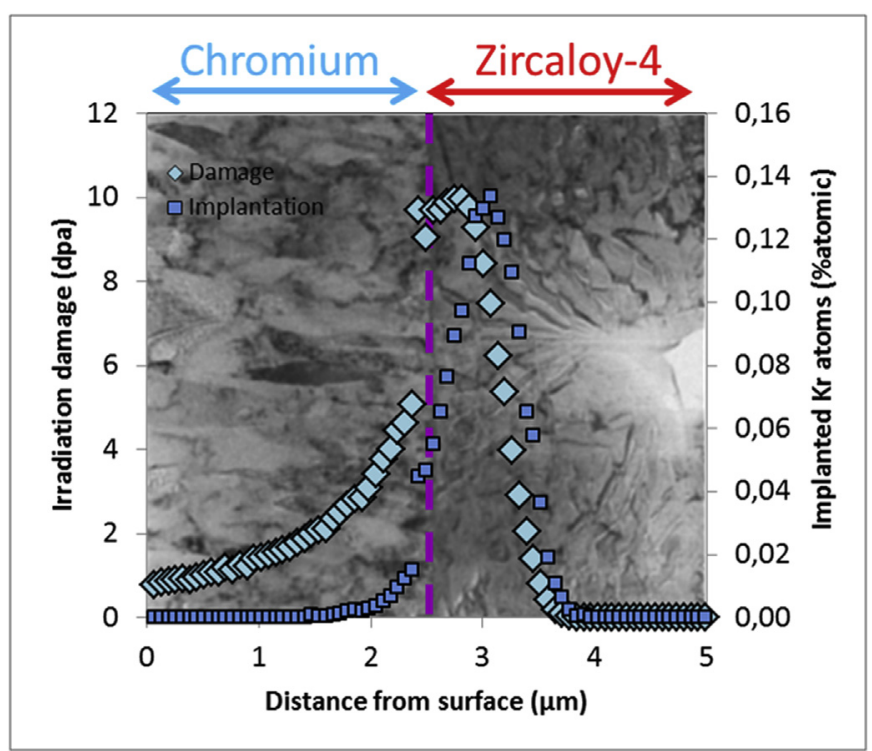

Fig. 1. SRIM calculated damage (Kinchin-Pease mode) at the interface chromium/zirconium alloy for $20 \mathrm{MeV} \mathrm{Kr}{ }^{8+}$ ions irradiation at a fluence of $4.8 \times 10^{15}$ ions.cm $^{-2}$ superimposed on a TEM micrograph.

treatment, a thin foil sample was prepared from a sample that went through the same temperature history as the irradiated sample ( $400^{\circ} \mathrm{C}$ - approximately $7 \mathrm{~h} 45 \mathrm{~min}$ : which corresponds to the irradiation time plus $30 \%$ for flux measurements).

\section{Results}

\subsection{Unirradiated sample}

Fig. 2a shows the unirradiated sample displaying both zirconium and chromium region. At this magnification, a contrasted band is observed at the interface with a thickness of $40-100 \mathrm{~nm}$. To determine the composition of this band, chemical composition of the interface was investigated. At least ten different EDS scans through the interface were collected. Fig. 3a presents the superposition of the different chromium and zirconium concentration profiles through the interface. It is seen that along the interface the chemical composition is quite homogeneous. The concentration profiles look alike interdiffusion profiles between zirconium and chromium elements. The interdiffusion area extends over $50 \mathrm{~nm}$. Further, for the particular sample studied here, from the chemical analyses, it has been noticed that the interface is slightly enriched in iron, which is linked to specific fabrication parameters that are not representative of the more industrial coatings. Fig. 4a shows the superposition of the iron concentration over the different sites explored at the unirradiated interface. However, discrepancies in the iron concentration are observed from one profile to the other one (compare Fig. 5a and b). The concentration varies at the interface from $1.5 \mathrm{wt}$ percent ( $\mathrm{wt} \%$ ) to $3.3 \mathrm{wt} \%$. The average concentration at peak is $2.3 \mathrm{wt} \%$. In chromium and Zirc-4, the average concentration is close to $0.2 \mathrm{wt} \%$. To understand the variation of iron concentration, the chemical analyses were correlated to their position in the sample. The variation of iron concentration observed on Fig. 5a and b could be related to the different chromium grain investigated, suggesting that the nature of the interface chromium/Zircaloy-4 (orientation of Zr hcp crystal to $\mathrm{Cr}$ bcc crystal) plays a role in the distribution of iron.

High Resolution TEM (HRTEM) observations were also performed at the interface. Along the interface, two zones were 
Table 1

Experimental irradiation conditions of the present study.

\begin{tabular}{|c|c|c|c|c|c|c|}
\hline \multirow[t]{2}{*}{ Material } & \multirow[t]{2}{*}{ Ions } & \multirow[t]{2}{*}{ Energy (MeV) } & \multicolumn{2}{|c|}{$\begin{array}{l}\text { Displacement damage at the } \\
\text { interface } \mathrm{Cr} / \mathrm{Zirc}-4\end{array}$} & \multirow[t]{2}{*}{$\begin{array}{l}\text { Fluence } \\
(\text { ions.cm } \\
\text { (ion) }\end{array}$} & \multirow[t]{2}{*}{$\begin{array}{l}\text { Temperature } \\
\text { (K) }\end{array}$} \\
\hline & & & $\left(\right.$ dpa.s $\left.^{-1}\right)$ & $\overline{\mathrm{dpa}}$ & & \\
\hline Chromium coated Zirc-4 & $\mathrm{Kr}^{8+}$ & 20 & $4.7 \times 10^{-4}$ & 10 & $4.8 \times 10^{15}$ & 673 \\
\hline
\end{tabular}

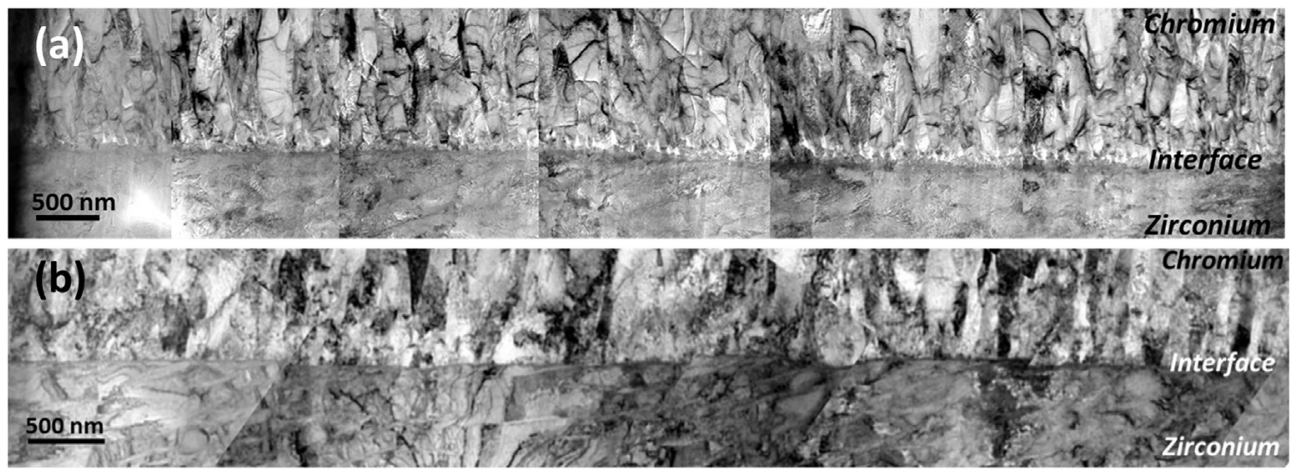

Fig. 2. TEM observation of a) the unirradiated interface b) the irradiated interface (FIB samples).

investigated, labelled Zone $A$ and Zone B in Fig. 6a. HRTEM observations of Zone $A$ (Fig. $6 \mathrm{~b}$ ) show the presence of Laves phases region below the chromium region which corresponds to the contrasted band. Four different regions with different structures can be observed. Regions 1, 2 and 3 correspond to Laves phases whereas Region 4 corresponds to the interface C14 phase with the chromium. Fig. $6 \mathrm{~b}$, thus, displays a complex polytype structure at the interface. It is constituted of an alternation of two phases. Indeed, Region 1 and 3 display the same structure whereas Region 2 is different. Also, it is noticeable that Region 1 and 3 are larger than Region 2. A deeper analysis of the different structures is presented on Fig. 7 and Fig. 8. On Fig. 7a, Fast Fourier Transform (FFT) of Region 1 indicates the presence of $\mathrm{C} 15$ metastable face cubic centered $\mathrm{Zr}(\mathrm{Fe}, \mathrm{Cr})_{2}$. This phase was observed with a typical $\mathrm{Zr}(\mathrm{Fe}, \mathrm{Cr})_{2}$ or $\mathrm{ZrCr}_{2}$ chemical stoechiometry by X.Q. Chen et al. [36] and V.N. Shishov et al. [37], with a lattice parameter equal to $\mathrm{a}=0.709-0.721 \mathrm{~nm}$. The lattice parameter calculated from the FFT is $\mathrm{a}=0.71 \mathrm{~nm}$, which is in agreement with the literature. The second phase found corresponds to $\mathrm{C} 14$ hexagonal closed packed $\mathrm{Zr}(\mathrm{Fe}, \mathrm{Cr})_{2}$ (Fig. 7b). Indeed, the FFT of this phase is found to be in zone axis $[1 \overline{2} 1 \overline{3}]$ and the calculated lattice parameters $\mathrm{a}=0.50 \mathrm{~nm}$ and $\mathrm{c}=0.82 \mathrm{~nm}$ are in agreement with the literature, that are $\mathrm{a}=0.504 \mathrm{~nm}$ and $\mathrm{c}=0.825 \mathrm{~nm}$ [38]. Fig. 7c presents the interface between these two structures. The two phases are coherent along the $\mathrm{C} 15$ [220] direction and the C14 [0111] direction. Region 4 is presented on Fig. 8a and corresponds to the interface between C14 $\mathrm{Zr}(\mathrm{Fe}, \mathrm{Cr})_{2}$ and chromium. The FFT shows that the lattice parameter of body-centered cubic (bcc) chromium is a $=0.28 \mathrm{~nm}$ which is in accordance with the literature that is $a=0.287 \mathrm{~nm}$ [39]. The HRTEM micrograph of this interface shows steps on the chromium side and a zigzag interface on the C14 Laves phase side. The interface with chromium could be considered as a ledged interface with an array of $[\overline{1} 10]_{\mathrm{bcc}}$ steps of different heights, while the interface with the Laves phase region presents a zigzag configuration. Also, there is plan continuity and atomic matching along the direction $[\overline{1} 10]_{\mathrm{bcc}}$ for chromium and $[01 \overline{11}]_{\mathrm{hcp}}$ for the C14-Laves phase can be noted. Fig. 8b presents the zirconium/Laves phase C14 (hcp) interface. From the FFT, an orientation relationship can be observed and

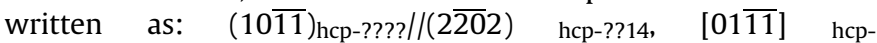
????//[1 $\overline{213}]_{\text {hcp-??14. }}$ On one hand, the $\mathrm{C} 14$ Laves phase is in zone axis
$[1 \overline{2} 1 \overline{3}]$, whereas on the other hand, zirconium is in zone axis

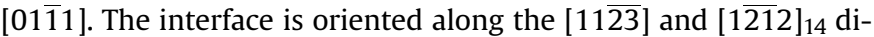
rection and can be described as an alternation of terraces and steps on both sides. On the $\mathrm{C} 14$ side, the terraces are contained in the (1011) plan. On the zirconium side, they are contained in the oriented along (2020)14 and a zigzag interface on the C14 Laves phase side. Also, there is plan continuity and atomic matching along $(011 \overline{2})$ and $(0 \overline{22} 2)_{14}$.

HRTEM observations of Zone $B$ (Fig. 6c) reveal another arrangement of the chromium/zircaloy- 4 interface from the one observed in Zone A (Fig. 6b). Fig. 9 presents the HRTEM imaging of Zone $\mathrm{B}$ and associated FFT. At this interface, which is just below Zone $A$, no Laves phases are observed. The interface is made of zirconium in zone axis $[1 \overline{2} 1 \overline{3}]$ and of chromium in zone axis [001]. The presence of these two zones with different interfaces proves the discontinuity of the Laves Phases and the complexity of their distribution along the interface. The interface between chromium and zirconium shows once again plan continuity. There is an orientation relationship between the two phases which is: $(1 \overline{2} 1 \overline{3})_{h c p-Z r} / /(001)_{b c c-C r}$ and $[1 \overline{1} 01]_{h c p-Z r} / /[110]_{b c c-C r}$. The interface is again a ledged interface on the chromium side with an array of [110 $]_{\mathrm{bcc}}$ steps of different heights.

To conclude on this analysis, the contrasted band observed corresponds to Laves phases (C14 or C15) and indicates that the interface Chromium/Zircalloy-4 is far from being abrupt, nor incoherent. The study of Zone A and B on the unirradiated sample highlights the fact that the chromium/zirconium alloy interface is complex and discontinuous even before irradiation. The different interfaces observed are crystalline and display atomic row matching. These results are in accordance with the paper of Ribis et al. [33] on the atomic-scale structure of Cr-coated Zircalloy-4 alloy.

\subsection{Irradiated sample}

As for the unirradiated sample, chemical analyses were performed on the irradiated interface. The interface studied has been irradiated up to $10 \mathrm{dpa}$ (Fig. 1a) with $\mathrm{Kr}$ ions at $400^{\circ} \mathrm{C}$.

Fig. $2 \mathrm{~b}$ shows the irradiated interface. At this magnification, the contrasted band observed on the unirradiated sample is still visible. As for the unirradiated sample, chemical composition of the 
(a)

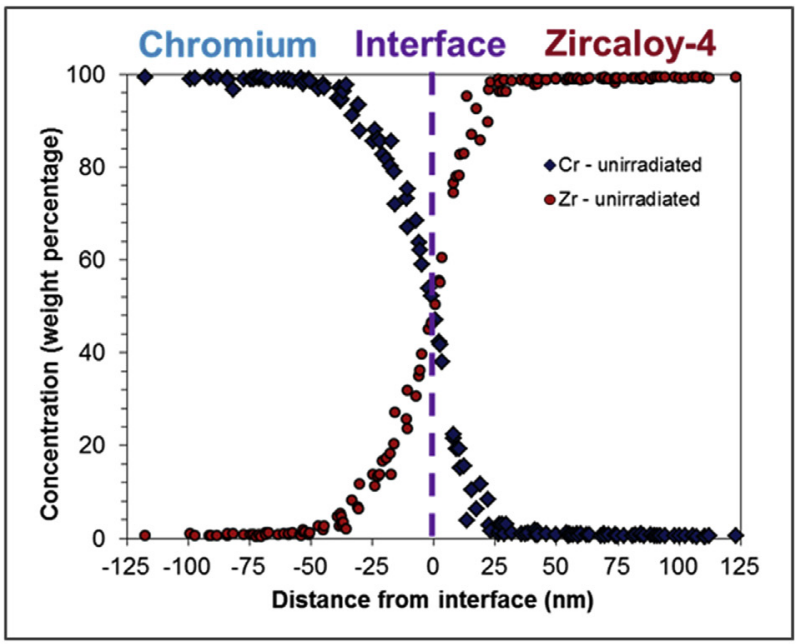

(b)

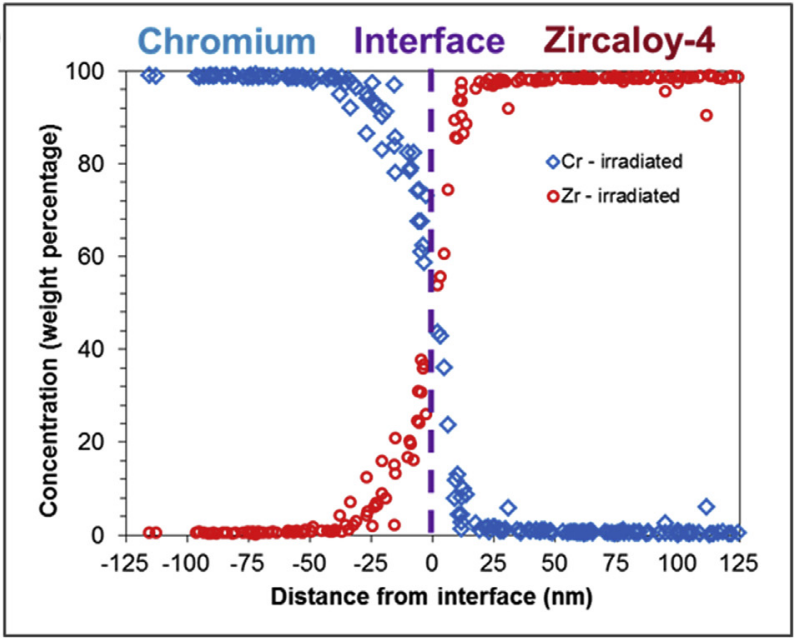

(c)

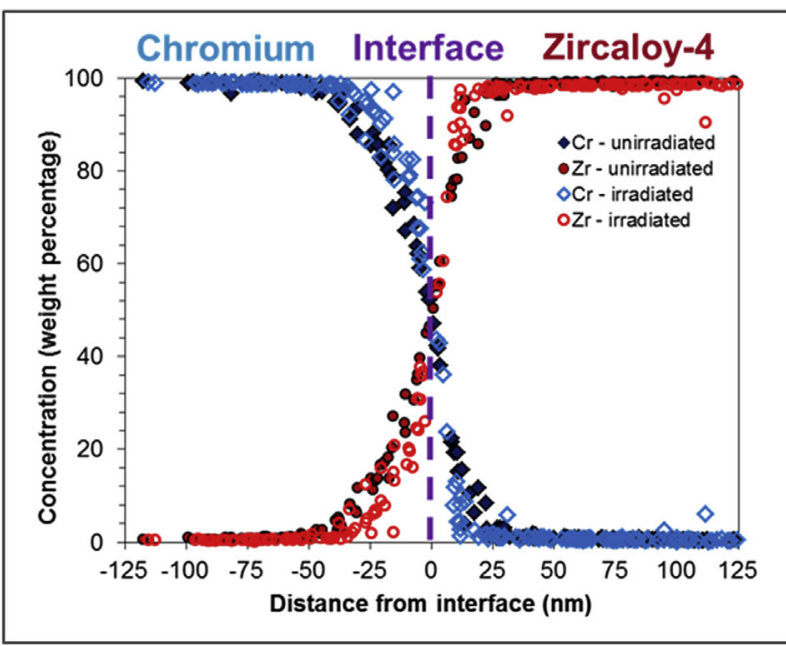

Fig. 3. Chromium and zirconium concentration profiles of a) the unirradiated interface b) the irradiated interface c) Overlap of the unirradiated and irradiated profile.

interface was investigated using EDS. Fig. 3b presents the superposition of the chromium and zirconium concentrations through the interface. The chemical composition is still homogeneous and the concentration profiles still looks alike interdiffusion profiles. Concerning the evolution of the iron enrichment previously observed on the unirradiated material, Fig. 4b shows iron (a)

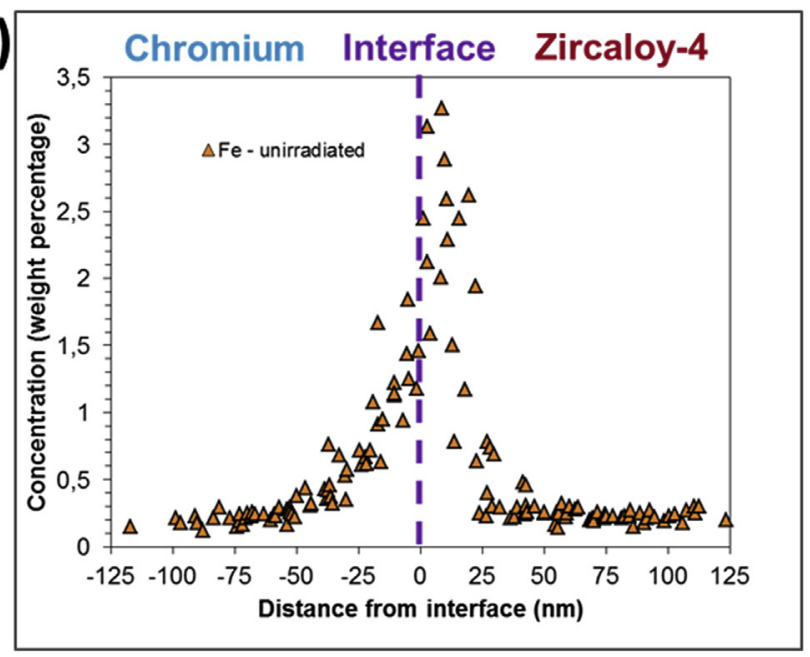

(b)

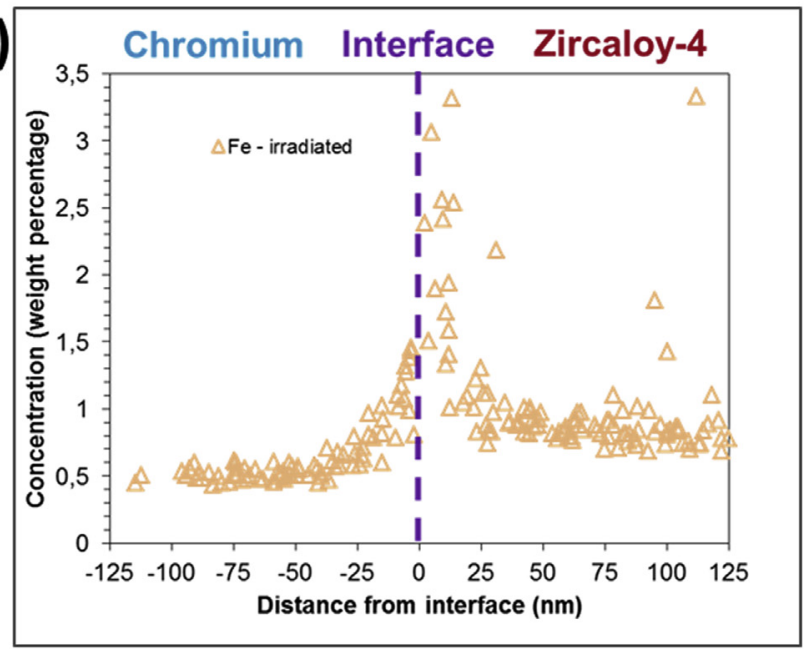

(c)

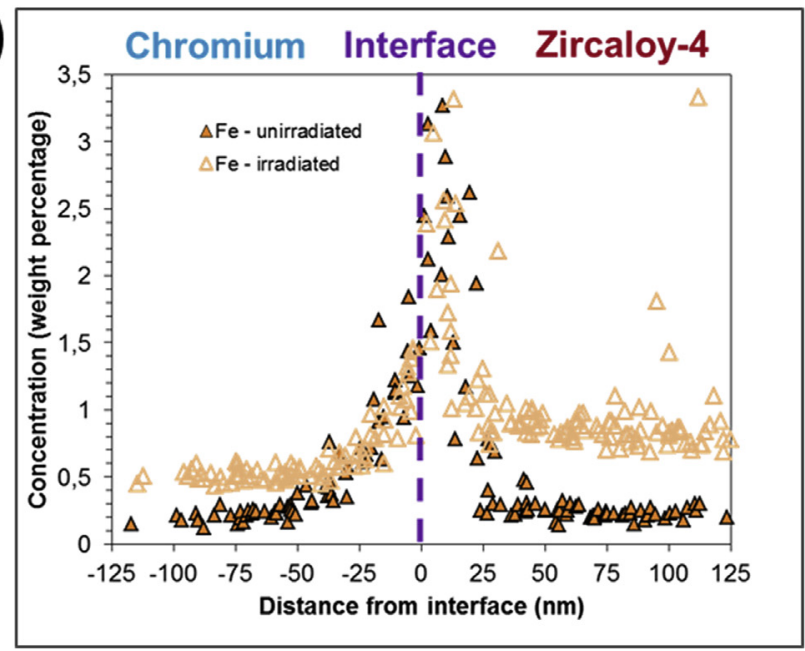

Fig. 4. Iron concentration of a) the unirradiated interface b) the irradiated interface c) Overlap of the average iron concentration of the unirradiated and irradiated sample: each point is an average over $20 \mathrm{~nm}$ distance.

concentration over the irradiated interface and Fig. $5 c$ and $d$ shows the separated eleven profiles. The iron concentration at peak varies from $1 \mathrm{wt} \%$ to $3.3 \mathrm{wt} \%$ with an average value of $2 \mathrm{wt} \%$. In chromium, the average concentration is $0.5 \mathrm{wt} \%$ and is close to $1 \mathrm{wt} \%$ in Zirc- 4 . 
(a)

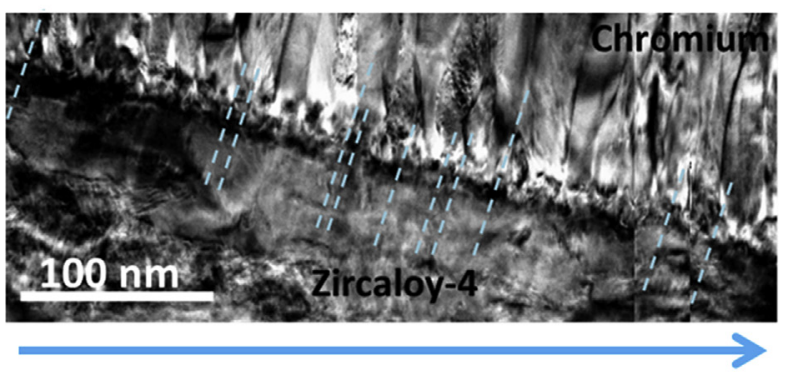

(c)

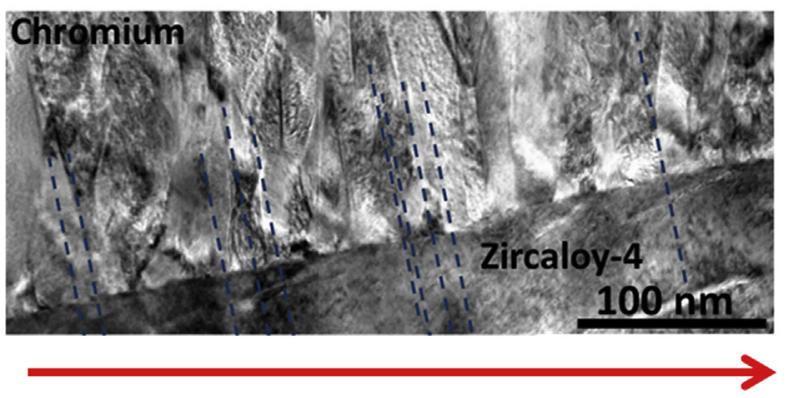

(b)
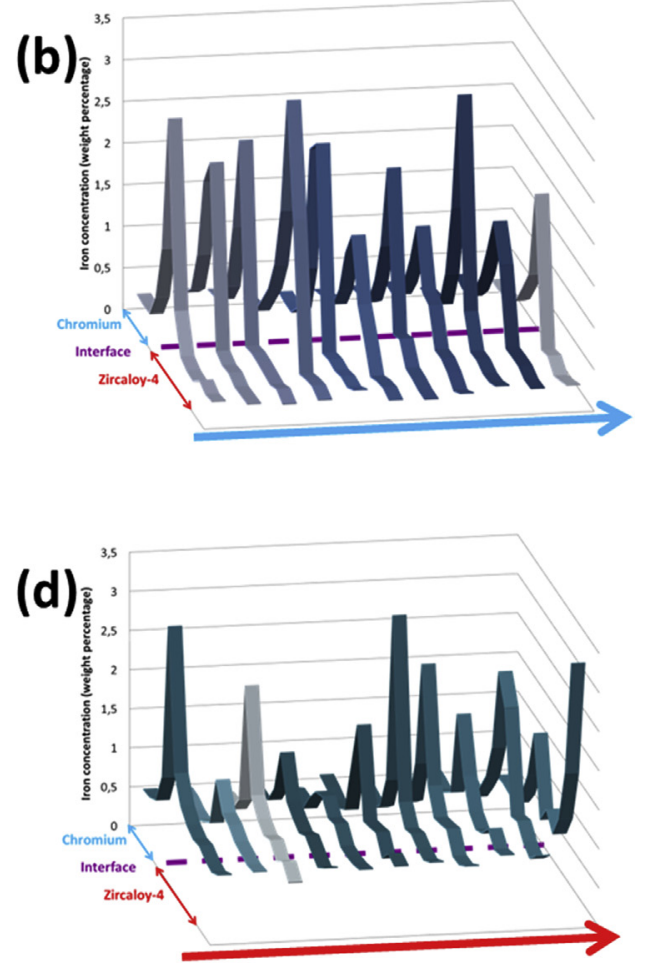

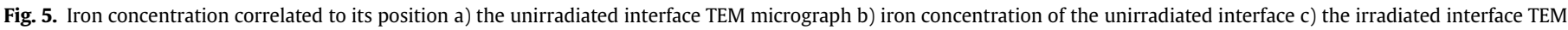
micrograph d) iron concentration of the irradiated interface.

(a)

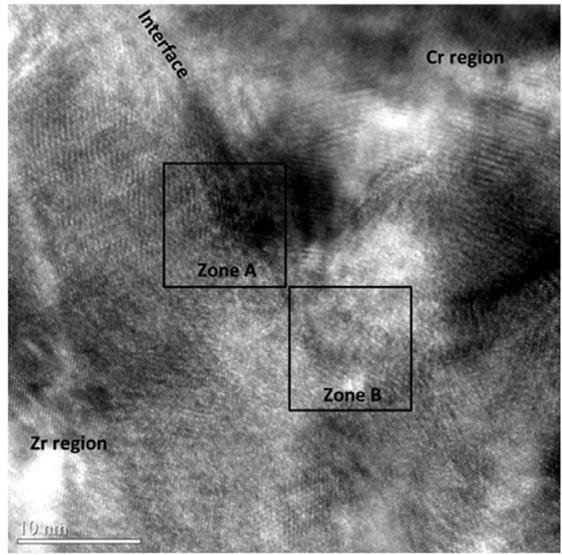

(b)

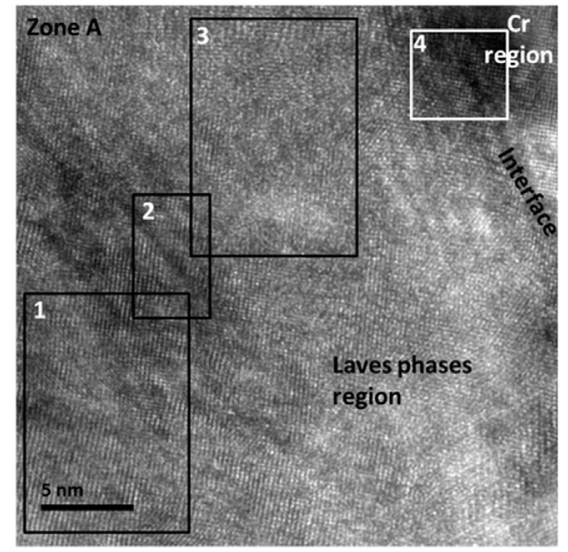

(c)

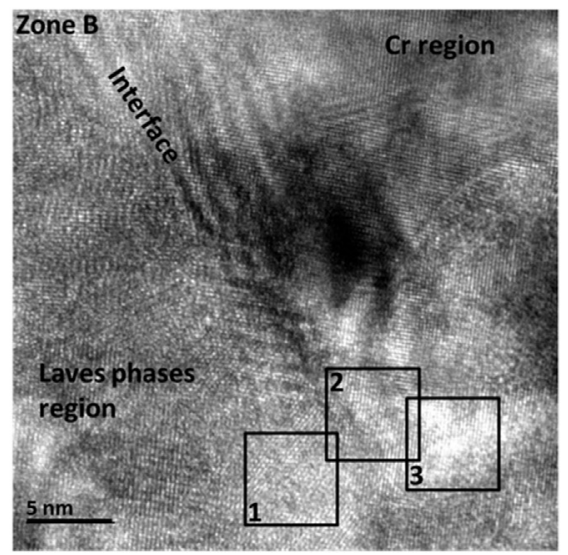

Fig. 6. a) High resolution cross sectional lattice imaging of unirradiated interface chromium/zirconium alloy b) Cross sectional HRTEM micrograph of the Laves phases region i.e. Zone A c) Cross sectional HRTEM micrograph of the interface of Zone B. 
(a)
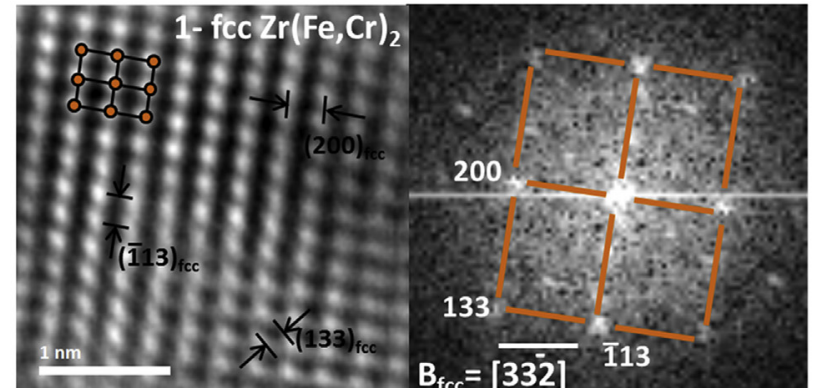

(b)

(c)
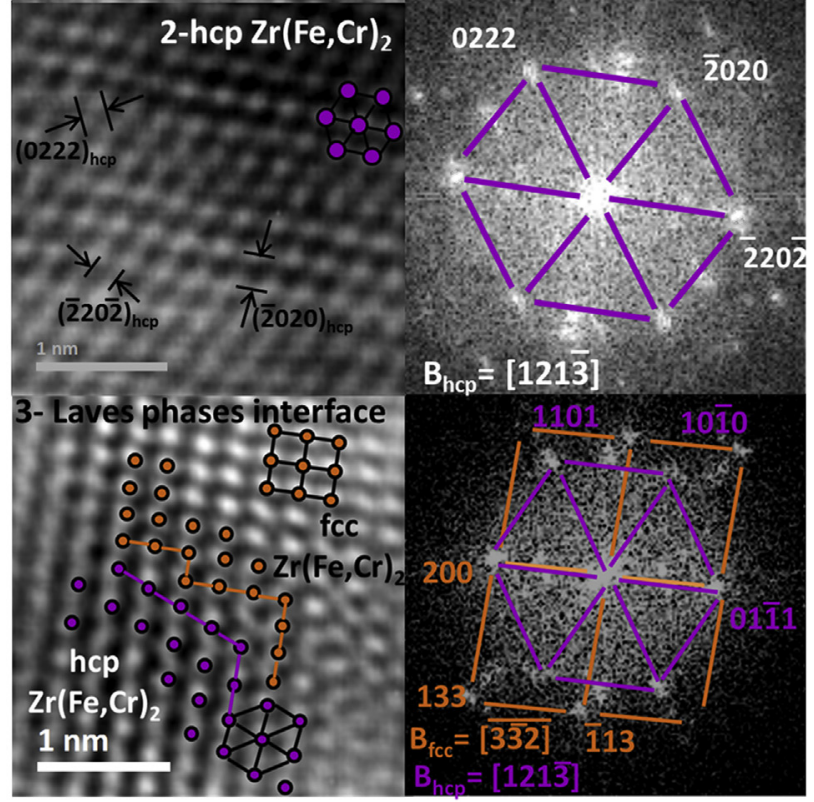

Fig. 7. Unirradiated sample - Zone A a) HRTEM imaging of Area 1 and associated FFT (b) HRTEM imaging of Area 2 and associated FFT (c) HRTEM imaging the phase transition between Area 1-2 and associated FFT.

(a)

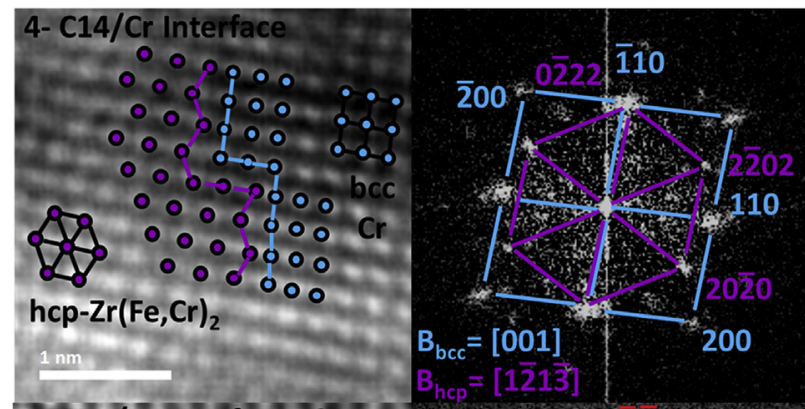

(b)

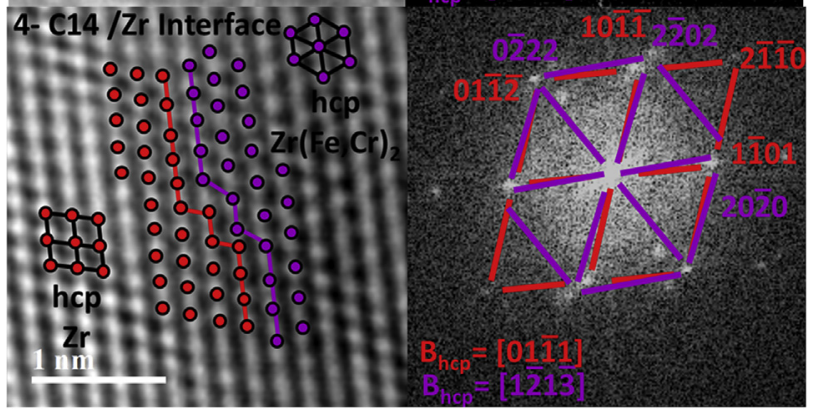

Fig. 8. Unirradiated sample - Zone A Area 4 (a) $\mathrm{C} 14 / \mathrm{Cr}$ interface HRTEM imaging and associated FFT (b) C14/Zr interface HRTEM imaging and associated FFT. (a)

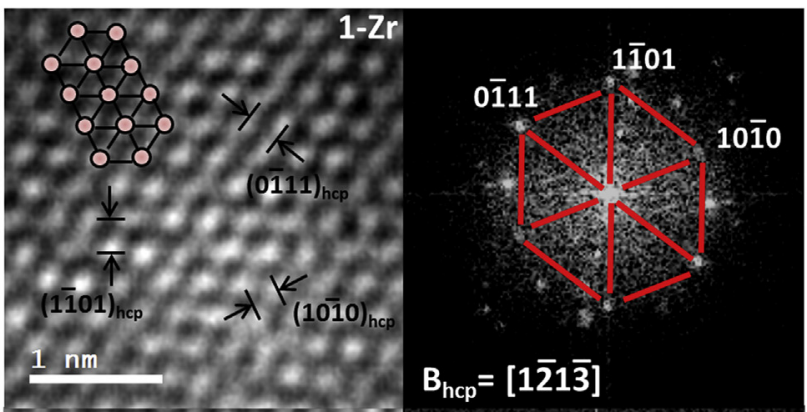

(b)

(c)
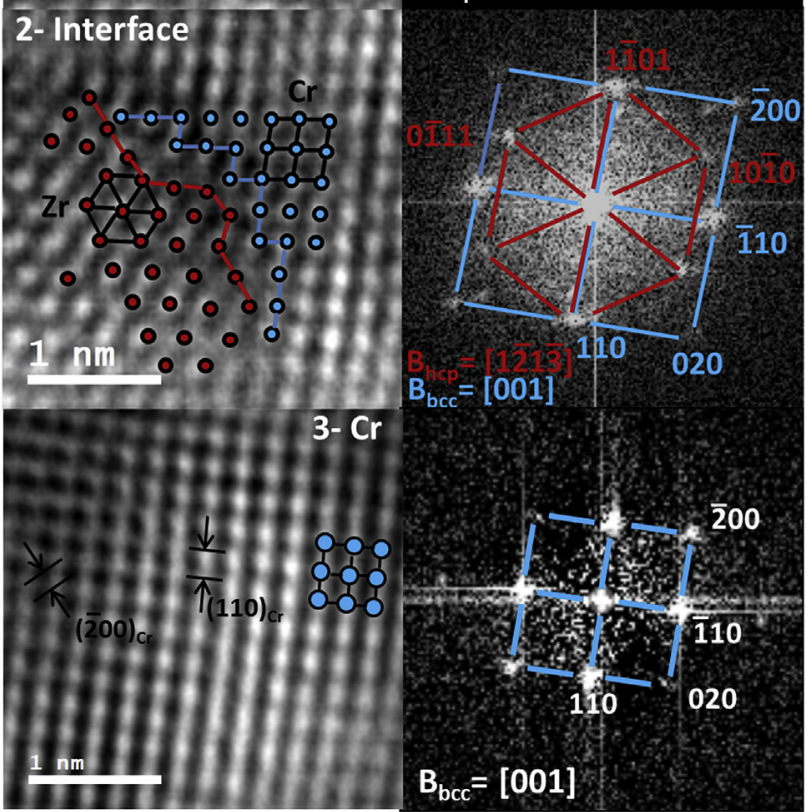

Fig. 9. Unirradiated sample - Zone B (a) HRTEM imaging of Area 1 and associated FFT (b) HRTEM imaging of Area 2 and associated FFT (c) HRTEM imaging of Area 3 and associated FFT.

The variation of iron concentration from one position to another is also observed for the irradiated sample on Fig. 5b.

When comparing the chemistry of the interface before and after irradiation (Fig. 3c), we can notice that the interface has slightly sharpened. This slight sharpening could be an artefact of the experiment, as the irradiation was not conducted in situ. However, some authors have reported interface sharpening on unirradiated interfaces, either due to heat treatment [40] or to large diffusion asymmetry across the interface owing to difference in vacancy formation and migration energies between the substrate and the coating [41]. Stress effects should also be considered as Erdely et al. [40] reported such mechanism as one of the most relevant effect. Also, internal stresses can enhance diffusion under irradiation [41,42], which may promote interface sharpening through enhanced demixing.

High Resolution TEM (HRTEM) observations along the interface were performed. Four zones were investigated (Fig. 11). HRTEM observations of Zone 1-3 show the presence of C14 (hcp) Laves phases $\mathrm{Zr}(\mathrm{Fe}, \mathrm{Cr})_{2}$ region between the chromium and the Zircaloy- 4 . The analysis of this region is performed on Fig. 12a. The FFT indicates that the phase in Zone 1 is in zone axis [21 2 2] and the lattice parameters calculated from it are equal to those found both before irradiation and in the literature $(\mathrm{a}=0.504 \mathrm{~nm}$ and $\mathrm{c}=0.825 \mathrm{~nm})$ [38]. The $\mathrm{Zr}(\mathrm{Fe}, \mathrm{Cr})_{2} \mathrm{C} 14$ phase presented in Zone 3 is oriented along the [0002] zone axis. Zones 2 and 4 present the interface of these two phases with zirconium. On Zone $2, \mathrm{Zr}$ is oriented along the 
$[1 \overline{2} 1 \overline{3}]$ zone axis and its calculated lattice parameters are equal to those found before irradiation $(\mathrm{a}=0.32 \mathrm{~nm}$ and $\mathrm{c}=0.51 \mathrm{~nm})$. On zone $4, \mathrm{Zr}$ is oriented along the [0001] zone axis (Fig. $13 \mathrm{a}$ and b). The different interfaces between $\mathrm{Zr}$ and $\mathrm{Zr}(\mathrm{Fe}, \mathrm{Cr})_{2}$ were studied and are illustrated in Fig. 13. Fig. 13a presents the interface between the hcp C14 Laves phase and Zr. The orientation relationship between those two is $(1 \overline{2} 1 \overline{3})_{Z r} / /(21 \overline{3} 2)_{C 14}$ and $[10 \overline{1} 0]_{Z r} / /[1 \overline{2} 10]_{C 14}$. As for the unirradiated interface, steps are observed on the C14 side between $\mathrm{C} 14 \mathrm{hcp} \mathrm{Zr}(\mathrm{Fe}, \mathrm{Cr})_{2}$ and $\mathrm{Zr}$. The interface could be considered as a ledged interface with an array of $[1 \overline{2} 10]_{\text {hcp }}$ steps. On the other hand, a disoriented interface below the one described in Fig. 13a was observed (Fig. 13b). The interface is not well defined on the high resolution image, although the FFT proves the presence of a misoriented interface. Indeed, the FFT shows a disorientation between all the directions (that is to say: $[\overline{1100}]_{\mathrm{hcp}-\mathrm{Zr}}$ and $[\overline{2} 200]_{\mathrm{hcp}-}$ C14; $[\overline{1100}]_{\text {hcp-Zr }}$ and $[\overline{2} 200]_{\text {hcp-C14 }} ;[\overline{1100}]_{\text {hcp-Zr }}$ and $\left.[\overline{2} 200]_{\text {hcp-C14 }}\right)$.

Fig. 14b presents the interface between chromium and Laves phase $\mathrm{C} 14 \mathrm{Zr}(\mathrm{Fe}, \mathrm{Cr})_{2}$. We notice that the crystallinity of the interface and atomic row matching between those two phases are kept after ion irradiation. The interface is disoriented and the FFT shows a disorientation between all the directions, that is to say: [011 $]_{\mathrm{bcc}-\mathrm{Cr}}$ and $[2200]_{\mathrm{hcp}-\mathrm{C} 14} ;[101]_{\mathrm{bcc}-\mathrm{Cr}}$ and [2020 $]_{\mathrm{hcp}-\mathrm{C} 14} ;[110]_{\mathrm{bcc}-\mathrm{Cr}}$ and $[0222]_{\text {hcp-C14 }}$. Concerning the structure of the interface, it is a ledged interface on the Laves phase side with steps along the [0222 $]_{\mathrm{hcp}-\mathrm{C} 14}$ direction and a zigzag interface on the chromium side.

To conclude on this analysis, the chemistry of the chromium/ Zircaloy- 4 interface does not change significantly after irradiation, even at the nanometric scale. Moreover, no $\mathrm{C} 15-\mathrm{fcc} \mathrm{Zr}(\mathrm{Fe}, \mathrm{Cr})_{2}$ phases were observed. Also the atomic row matching and crystallinity is kept after ion irradiation between $\mathrm{C} 14 \mathrm{Zr}(\mathrm{Fe}, \mathrm{Cr})_{2} / \mathrm{Zr}$ and $\mathrm{C} 14$ $\mathrm{Zr}(\mathrm{Fe}, \mathrm{Cr})_{2} / \mathrm{Cr}$. The presence of two misoriented interfaces after irradiation (Figs. 13b and 14b) has to be noted.

\subsection{Heat treated sample}

After studying the irradiated interface, the heat treated reference is studied to separate the potential effect of thermal annealing from the pure irradiation contribution. For that purpose, FIB thin foil was extracted from a sample that went through the same temperature history as the irradiated sample $\left(400^{\circ} \mathrm{C}-8 \mathrm{~h}\right)$.

EDS chemical analyses from both the ion-irradiated and the heat treated samples were compared (Fig. 10). The chromium and zirconium concentration profiles are very similar (even though the concentration profiles are a little bit more scattered after heat treatment). Concerning the iron concentration, it is observed that after irradiation, there is a rise of the iron concentration in the vicinity of the interface, while no rise of iron concentration has been observed after thermal annealing. Therefore, the rise of iron concentration could be attributed to irradiation.

\section{Discussion}

\subsection{Zirc-4/Cr interface before irradiation}

\subsubsection{Atomic structure}

Before irradiation, the HRTEM images of the $\mathrm{Cr} / \mathrm{Zirc}-4$ interface reveal a complex interface atomic structure varying along the interface region (Fig. 6). These variations are due to the existence of small $\mathrm{Cr}$ grains with distinct orientations at the interface and also to the chemical variation between the different interfaces. Indeed, the chemistry at the interface varies with the relative orientation of chromium grains compared to zirconium grains. This multiplicity of relative orientations induces different interfaces and as an atom diffuses preferentially along some directions in the zirconium, and as all the zirconium grains are not oriented in the same direction,

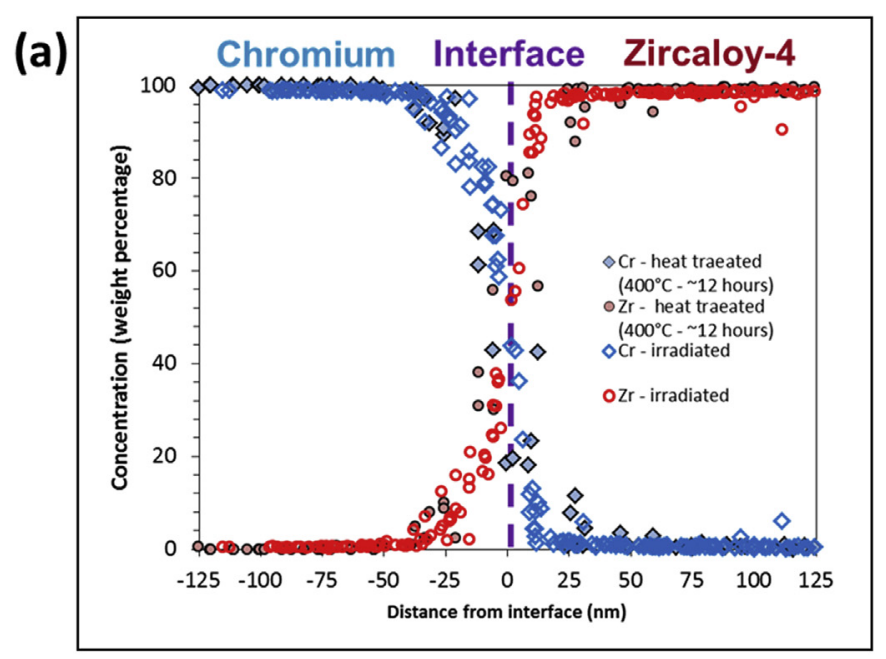

(b)

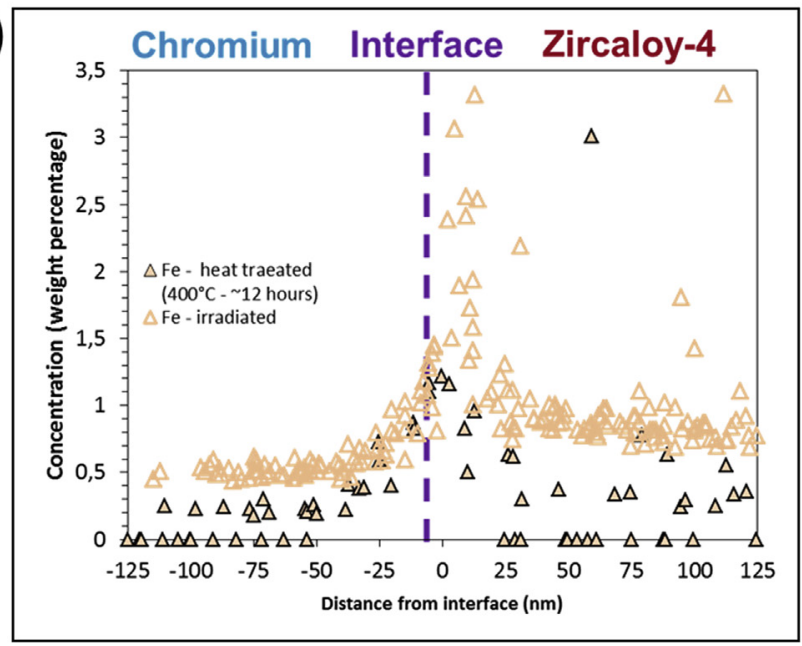

Fig. 10. (a) Chromium and zirconium concentration profiles of the as-received interface supperimposed to the heat treated sample $\left(400^{\circ} \mathrm{C}-12 \mathrm{~h}\right.$ ) (b) Iron concentration profile of the as-received interface supperimposed to the heat treated sample $\left(400^{\circ} \mathrm{C}-12 \mathrm{~h}\right)$

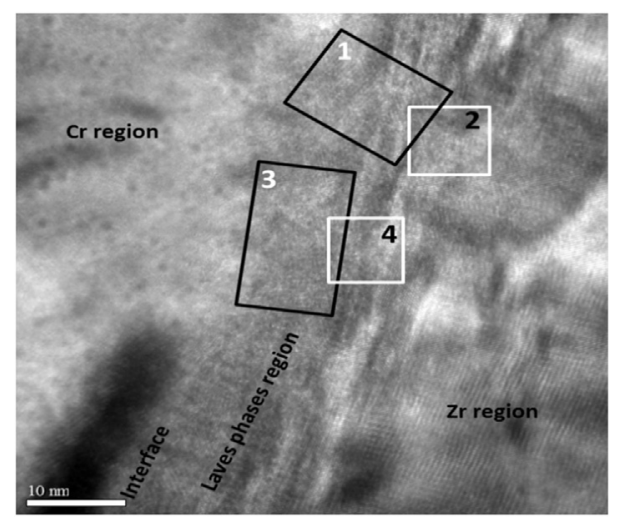

Fig. 11. High resolution cross sectional lattice imaging of irradiated interface chromium/zirconium alloy.

then the chemistry at the $\mathrm{Cr} / \mathrm{Zr}$ interface varies. The lattice images of the different interfaces found, either between C14 and chromium (Fig. 8b) or between chromium and zirconium (Fig. 9b), demonstrate that the crystalline structure is preserved throughout the 


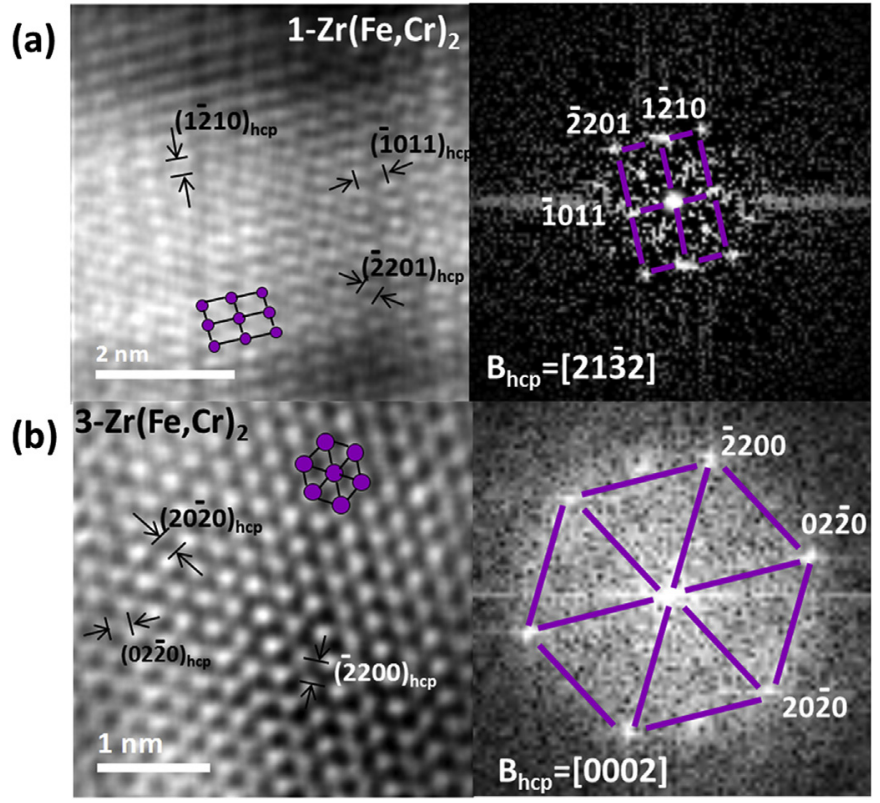

Fig. 12. Irradiated sample - C14 Laves phases (a) HRTEM imaging of area 1 and associated FFT (b) HRTEM imaging of Area 3 and associated FFT.

interface region. The inter-phase between $\mathrm{C} 14$ and $\mathrm{C} 15$ shown on Fig. $7 \mathrm{c}$ also presents a crystalline structure. The atomic planes of the coating are observed to be in direct contact with the atomic planes of the Laves phase, and the atomic planes of the Laves phases are also observed to be in direct contact with each other, indicating a fully dense interface. Figs. 7c, 8 and 9b show atomic row matching

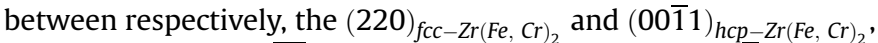
the $(001)_{C r}$ and $(01 \overline{11})_{h c p-Z r(F e, C r)_{2}}$, the $(110)_{C r}$ and $(1101)_{Z r}$. As pointed out by Ribis et al. [33] for a thicker $\mathrm{Cr}$ coating, this crystal continuity visible over several micrometers is a strong evidence pointing towards local heteroepitaxy. Also, they state that this high degree of local epitaxial growth achieved using the HIPIMS technique is expected to translate into strong adhesion of the overall coating. They also model the interface structure in order to identify likely structure and the atom to atom coherence relationships, since the HRTEM images do not directly reveal atomic positions. The interface that they observed also displays C14 and C15 $\mathrm{Zr}(\mathrm{Fe}, \mathrm{Cr})_{2}$ Laves phases so that their conclusions can also be applied to our interface. They reported that the interface which displays a zigzag structure presents a high degree of coherency despite the lattice parameter misfit. They also discuss the mechanical properties of such interface and state that the Laves phases formation allows a gradually variation of the mechanical properties (elastic modulus) at the interface thus participating to the good adhesion of the coating on the substrate and to good overall mechanical properties at the macroscopic scale.

\subsubsection{Chemical composition}

It has to be noted that the physical interface between $\mathrm{Zy}-4$ alloy and chromium is hard to define because we do not know the value of the chromium diffusion coefficient in the Laves phases $D_{C r \rightarrow C 14 / C 15}$, nor the zirconium diffusion coefficient in the Laves phases $D_{Z r \rightarrow C 14 / C 15}$. Indeed, according to the Kirkendall effect, if one of the diffusion coefficients is higher than the other, the interface moves in the opposite direction than the higher elemental flux. Not knowing those values, we arbitrarily chose the $\mathrm{Cr} / \mathrm{Zy}-4$ physical interface where there is $50 \%$ wt of chromium and $50 \% \mathrm{wt}$ of zirconium. Moreover, the chemical profiles were made on
$250 \mathrm{~nm}$ across the interface, the following results present tendencies over this whole interface region.

Before irradiation, an interdiffusion-like profile is observed (Fig. 3a). As explained by Ehiasarian et al. [43] on another system ( $\mathrm{CrN}$ or $\mathrm{CrN} / \mathrm{NbN}$ based coatings on stainless steel substrate), this observation could be due to the PVD-type process consisting in a highly energetic pretreatment that forces the intermixing of elements at the interface and also promotes diffusion due to a local rise of temperature. However it has to be mentioned that the observed $\mathrm{Cr}-\mathrm{Zr}$ inter-diffusion spatial extent is limited to approximately $100 \mathrm{~nm}$.

Also, for this first generation chromium coated sample, some iron enrichment is observed at the interface before ion irradiation (Fig. 4a). Iron is believed to come from the zirconium alloy as the chemical composition of the industrial grade Zircaloy-4 exhibits $\sim 0.2 \mathrm{wt} \%$ of iron. It is assumed that iron segregates at the interface because it is thermodynamically favorable. S.A. Dregria and P. Wynblatt [44] have seen the same phenomenon on the segregation of $\mathrm{Au}$ on a $\mathrm{Cu}-\mathrm{Ag}$ interface at $500 \mathrm{~K}$. They have shown that $\mathrm{Au}$ segregates significantly at the interface (when present as an impurity at first in the system $\mathrm{Cu}-\mathrm{Ag}$ ) and reduces the interfacial energy. In the case of the particular sample studied here, during the deposition process, the Zirc-4 substrate should have undergone some temperature incursion not representative of more industrial coatings, which should be responsible for the slight Fe segregation observed at the $\mathrm{Zr}$-Cr interface in as-received conditions. Also, Fig. 5 shows the dependence of iron concentration with the different interfaces (relative orientation of chromium grains compared to zirconium grains) which is also predicted by their model. Indeed, the diffusing atoms have preferential diffusion directions, thus explaining the different iron concentration at the different interfaces. In addition to that, the different interfaces do not have the same interfacial energies. Thus, assuming that the segregation of $\mathrm{Fe}$ atoms is thermodynamically favored to lower the interfacial energy of the system, the different interfaces do not need the same amount of Fe atoms to reach a "local thermodynamic equilibrium". The segregation of iron at a chromium/Zircaloy-2 (Zirc-2) interface has also been observed by W. Xiang and S. Ying [45], when heating a chromium/Zirc-2 diffusion couple but for much higher annealing time and temperature (up to $1023 \mathrm{~K}$ for $49 \mathrm{~h}$ ). At this temperature, just below the allotropic transformation of $\mathrm{Zr}_{\alpha}$ into $\mathrm{Zr}_{\beta}$, formation of intermetallic phases $\mathrm{Zr}(\mathrm{Fe}, \mathrm{Cr})_{2}$ was observed at the interface. Upon further heating at this temperature, they observed the thickening of the intermetallic layer. Moreover, it has to be mentioned that Fe is an ultrafast (interstitial-like) diffusor in $\alpha$-Zr which could favor its (fast) segregation at the planar $\mathrm{Zr} / \mathrm{Cr}$ interface at quite low temperature [46-50].

For the particular Cr-coated zircaloy-4 sheet sample studied here, Laves phases C14-hcp $\mathrm{Zr}(\mathrm{Fe}, \mathrm{Cr})_{2}$ and $\mathrm{C} 15-\mathrm{bcc} \mathrm{Zr}(\mathrm{Fe}, \mathrm{Cr})_{2}$ were found at the interface. Although these two phases are found in industrial grade Zircaloys [51-55], their presence at the interface is likely related to the iron enrichment. As confirmed by thermodynamic calculation using "Thermocalc" and "Zircobase" thermodynamic tools [56] and discussed by Ribis et al. [33], the stability of C14-hcp is favored by Fe addition as it increases the average electron concentration ratio (e/a) which is defined for transition elements as the average number of $(p+d)$ electrons per atom. Thus, localized Fe enrichment or depletion at the interface observed on Fig. 5 may explain the presence of either $\mathrm{C} 14 \mathrm{hcp} \mathrm{Zr}(\mathrm{Fe}, \mathrm{Cr})_{2}$ or $\mathrm{C} 15$ bcc $\mathrm{Zr}(\mathrm{Fe}, \mathrm{Cr})_{2}$ at the interface. Indeed, the diffusion of Fe depends on the orientation of the zirconium crystal enabling to reach the interface faster or slower if the Fe atoms diffuse along the a-axis or the c-axis. Also, the relative orientations of $\mathrm{Cr}$ grains compared to $\mathrm{Zr}$ grains do not have the same interfacial energies, thus different iron atomic concentrations are needed between the different interfaces 
to reach their equilibrium state. The iron concentration at the interface thus depends on the nature of the interface that is to say to the local orientation of adjacent $\mathrm{Zr}_{\alpha}$ grains to the chromium grain.

\subsection{Zirc-4/Cr interface after irradiation}

\subsubsection{Atomic structure}

After irradiation, a multiplicity of interface's natures are still found: supposedly coherent interface between C14-hcp $\mathrm{Zr}(\mathrm{Fe}, \mathrm{Cr})_{2}$ and the substrate (Fig. 13a) as well as misoriented interfaces are observed. However, the plan continuity has been kept during irradiation which proves the good microstructural stability of the interface after irradiation for the tested conditions, even if C15 phases seem to have disappeared. Overall, the crystallinity of the interface is kept after irradiation as the plan continuity. This tends to ensure the residual good coating adhesion by avoiding a too sharp decrease of the elastic modulus when going from chromium to zirconium [33]. Note that investigations on the mechanical properties of ion irradiated $\mathrm{Cr} /$ Zirc- 4 interface are in progress.

\subsubsection{Chemical composition}

After ion irradiation up to $10 \mathrm{dpa}$ at $400^{\circ} \mathrm{C}$ the interface, no $\mathrm{C} 15$ phases are observed. It could be explained because TEM examination is very local and the C15 phase was not found in the limited spatial zone observed on the FIB lamella by HRTEM. However, it could also be explained by the rise of Fe concentration in the vicinity of the interface (Fig. 4b), which increases the e/a ratio and stabilizes the $\mathrm{C} 14$ over the $\mathrm{C} 15$, thus leading to the disappearance of C15 phases after ion irradiation. To confirm the potential disappearance of $\mathrm{C} 15 \mathrm{Zr}(\mathrm{Fe}, \mathrm{Cr})_{2}$, in situ TEM irradiation experiments are on-going at CEA, up to a higher irradiation damage dose.

Conventionally, under neutron irradiation, the $\mathrm{Zr}(\mathrm{Fe}, \mathrm{Cr})_{2}$ phases are subjected to crystalline to amorphous transformation [55-57]. Under ion-irradiation, the same phenomenon is observed. Amorphisation of $\mathrm{Zr}(\mathrm{Fe}, \mathrm{Cr})_{2}$ is reported but depends on irradiation temperature, doses reached and fluences [55,58-60]. For example, under $\mathrm{Kr}^{8+}(97.5 \mathrm{MeV})$ ion irradiation, amorphisation of $\mathrm{Zr}(\mathrm{Fe}, \mathrm{Cr})_{2}$

(a)

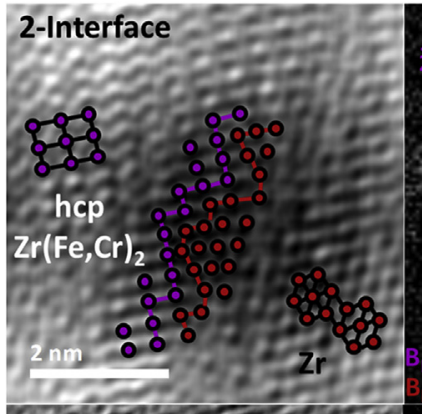

(b)

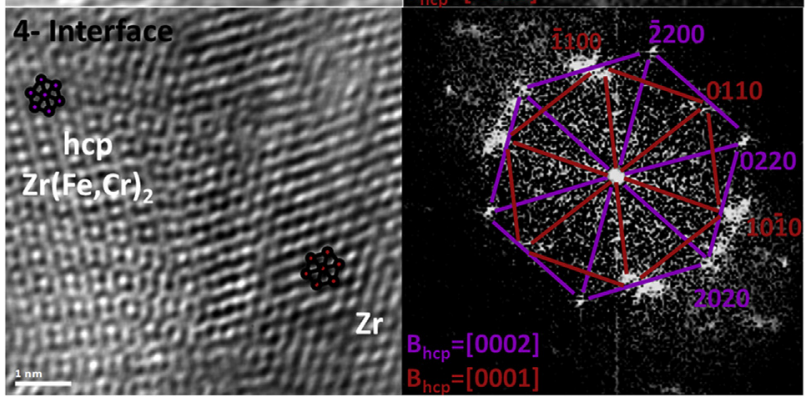

Fig. 13. Irradiated sample $-C 14 / Z r$ interface (a) HRTEM imaging of area 2 and associated FFT (b) HRTEM imaging of Area 4 and associated FFT.
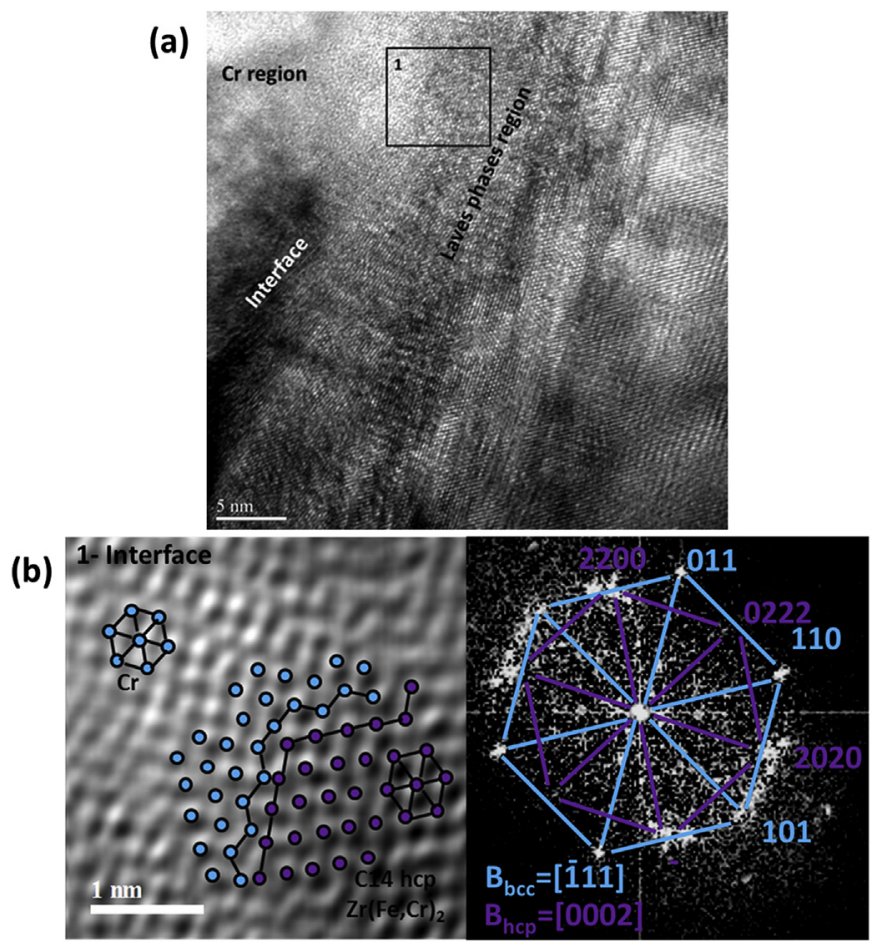

Fig. 14. Irradiated sample $-\mathrm{Cr} / \mathrm{Zr}$ interface (a) High resolution cross sectional lattice imaging of irradiated interface chromium/zirconium alloy (b) HRTEM imaging of Area 1 and associated FFT.

is observed at $602{ }^{\circ} \mathrm{C}$ for $100 \mathrm{dpa}$ at a fluence of $1.6 \times 10^{16}$ ion$\mathrm{s} . \mathrm{cm}^{-2}$. The displacement production was $2.8 \times 10^{-3}$ dpa.s ${ }^{-1}$ [60]. $\mathrm{F}$. Lefebvre et al. [60] explained the amorphisation thanks to collision cascades induced by heavy ion irradiation which destabilizes the $\mathrm{Zr}(\mathrm{Fe}, \mathrm{Cr})_{2}$ phases. The disorder induced by irradiation acts then as the driving force for amorphisation. In both neutrons and ions irradiations, destabilization of $\mathrm{Zr}(\mathrm{Fe}, \mathrm{Cr})_{2}$ by irradiation accounts for the amorphisation. The ion irradiation study presented in this paper does not show any amorphisation of $\mathrm{Zr}(\mathrm{Fe}, \mathrm{Cr})_{2}$. The experimental irradiation conditions of our experiment are reminded in Table 1 . Compared to the $\mathrm{Kr}$ ions irradiation realized by F. Lefebvre et al. [60], the ion irradiation realized in the present study occurs at lower temperature and the displacement damage is one order of magnitude lower than theirs. It is thus possible that the irradiation damage at the Zirc-4/Cr interface is too low to induce any intermetallic phases amorphisation. However, at $400{ }^{\circ} \mathrm{C}$ iron is highly mobile in $\alpha-\mathrm{Zr}$ and irradiation could induce an interstitial state in irradiated $\mathrm{Zr}$ which enhances its diffusion as reported by Griffith et al. [56].

Fig. 3c shows the overlap of the chromium/zirconium concentration profiles through the interface before and after ion irradiation. It is observed that after irradiation, the concentration profiles did not change much. This result is surprising as ion irradiation was reported to accelerate interdiffusion at interfaces by ion-beam mixing. Several authors reported intermixing at the metal-metal interface at room temperature [61-64]. However, the ion beam mixing is found at low temperature (typically room temperature) whereas the irradiation performed in this present study was made at $400^{\circ} \mathrm{C}$.

When looking at the concentration profile of Fe before and after irradiation, we may notice that there has been during the irradiation process an incoming flux of iron from the zirconium region to the chromium region through the interface. This effect is believed 
to be mainly due to irradiation as no additional Fe enrichment is observed on the $400^{\circ} \mathrm{C}$ heat treated unirradiated sample (Fig. 10b). Also, at this temperature, the chromium/zirconium concentration profile does not change compared to the unirradiated non-heated sample. Thus, irradiation should be responsible for the (slight) additional diffusion of iron at the interface. This diffusion can either be explained by the ion beam mixing or by the accelerated diffusion of iron under irradiation.

The increase in iron concentration should stabilize the C14 phases. The amorphisation of $\mathrm{Zr}(\mathrm{Fe}, \mathrm{Cr})_{2}$ is not observed as the irradiation damage is too low to destabilize enough the phases. It can be assumed that the iron comes from the partial dissolution of Secondary Phase Particles (SPPs) of the zircaloy-4 substrate near the interface under irradiation. This phenomenon has been reported under irradiation by several authors but needs to be verified. To assess this assumption, more experiments are on-going on the same material. In particular, carbon replicas of the Zirc-4 SPP's before and after ion irradiation are being produced and will be observed to confirm - or not - their potential loss of iron after irradiation.

In the end, in our specific irradiation conditions, the interface appears stable. However since the irradiation has been conducted on a short time period, the stability of the interface under neutron irradiation is not guarantee and will be the subject of a further work.

\section{Conclusion}

Chromium coated zirconium alloys are potential candidates as Enhanced Accident Tolerant Fuel for LWRs. In this study, the behavior of these materials after irradiation is assessed. To do so, a first experiment of ion irradiation was performed on first generation chromium coated $\mathrm{Zy}-4$ using $20 \mathrm{MeV} \mathrm{Kr}{ }^{8+}$ at $400{ }^{\circ} \mathrm{C}$ with a damage at the interface of $10 \mathrm{dpa}$. The unirradiated, heat-treated and irradiated materials are characterized by means of High Resolution Transmission Electron Microscopy and Energy Dispersive Spectrometry. For this particular sample, before irradiation, a polytype interface layer of 50-100 $\mathrm{nm}$ in thickness and consisting of a mixture of $\mathrm{Zr}(\mathrm{Fe}, \mathrm{Cr})_{2} \mathrm{C} 14$ and $\mathrm{C} 15$ phases is observed. Their respective interface structures were investigated at atomic scale in distinct zones along the interface region. Different atomic configurations are reported suggesting a large variety of interface structure along the interface region. Crystallinity throughout the $\mathrm{Cr} / \mathrm{Zr}$ interface and atomic row matching of the different interfaces was observed. After irradiation atomic row matching is kept. However misoriented interfaces were observed as well as the C15 disappearance. This disappearance is believed to be due to the continuous incoming flux of iron at the interface during irradiation which stabilizes the C14. Overall, good chemical and microstructural stability of the $\mathrm{Zr} / \mathrm{Cr}$ interface is observed after this specific ion irradiation. On-going tensile tests of ion-irradiated coated samples show a high residual adhesion of the Cr-coating, thus in good agreement with the microstructural and microchemical observations reported in the present paper.

\section{Acknowledgments}

The authors would like to thank Pr. A. Billard and G. Veliza from Université Technologique de Belfort-Montbéliard (France) for carrying out the chromium coatings deposition.

Finally AREVA NP (and especially J. Bischoff and C. Delafoy) and EDF (especially E. Pouillier and A. Ambard) are acknowledged for their financial support and fruitful discussions.

\section{References}

[1] Z. Yao, J.J. Stiglich, T.S. Sudarshan, Molybdenum silicide based materials and their properties, J. Mater. Eng. Perform. 8 (1999) 291-304.

[2] S. Tae Park, R.H. Baney, Thermal oxidation of Electron Beam Evaporator Deposited Aluminum Films on Zircaloy and Hydrothermal Reactions in Subcritical Aqueous Conditions, Abstract 74, 204th Meeting, The Electrochemical Society, Inc, 2003.

[3] R. Hui, W. Cook, C. Sun, Y. Xie, P. Yao, J. Miles, R. Olive, J. Li, W. Zheng, L. Zhang, Deposition, characterization and performance evaluation of ceramic coatings on metallic substrates for supercritical water-cooled reactors, Surf. Coating. Technol. 205 (2011) 3512-3519.

[4] S. Tae Park, Amorphous alumina oxidation protective coatings for Zircaloy based on a compositional gradient layer system, in: Proceedings $39^{\text {th }}$ International Conference on Metallurgical Coatings and Thin Films, San Diego, California, USA, 2012 April, pp. 23-27.

[5] H.-G. Kim, I.-H. Kim, J.-Y. Park, Y.-H. Koo, Application of Coating Technology on Zirconium-based Alloy to Decrease High-temperature Oxidation, Zirconium in the Nuclear Industry, 17th International Symposium, Hyderbad, Andhra Pradesh, India, 2013 Feb. 3-7.

[6] J.-Y. Park, I.-H. Kim, Y.-I. Jung, H.-G. Kim, D.-J. Park, B.-K. Choi, High temperature steam oxidation of Al3Ti-based alloys for the oxidation-resistant surface layer on Zr fuel claddings, J. Nucl. Mater. 437 (2013) 75-80.

[7] K.A. Terrani, C.M. Parish, D. Shin, B.A. Pint, Protection of zirconium by alumina- and chromia-forming iron alloys under high-temperature steam exposure, J. Nucl. Mater. (2013) 64-71.

[8] S. Mato, G. Alcalá, M. Brizuela, R. Escobar Galindo, F.J. Pérez, J.C. SánchezLópez, Long - term high temperature oxidation of $\mathrm{CrAl}(\mathrm{Y}) \mathrm{N}$ coatings in steam atmosphere, Corrosion Sci. 80 (2013) 1-153.

[9] A.T. Nelson, E.S. Sooby, Y.-J. Kim, B. Cheng, S.A. Maloy, High temperature oxidation of molybdenum in water vapor environments, J. Nucl. Mater. 448 (2013) 441-447.

[10] V. Avincola, High Temperature Steam Performance of Coatings for Zircaloy 20th International Quench Workshop, Karlsruhe, Germany, 2014 Nov. 11-14.

[11] H.-G. Kim, I.-H. Kim, Y.-I. Jung, D.-J. Park, J.-Y. Park, Y.-H. Koo, Microstructure and mechanical strength of surface ODS treates Zircaloy-4 sheet using laser beam scanning, Nuc. Eng. and Tech 46 (4) (2014).

[12] A.S. Kuprin, V.A. Belous, V.N. Voyevodin, V.V. Bryk, R.L. Vasilenko, V.D. Ovcharenko, G.N. Tolmachova, P.N. V'ygov, High temperature air oxidation of E110 and Zr-1 Nb alloys claddings with ISSN 1562-6016 1 (89) (2014) $126-133$.

[13] C. Tang, Oxidation Resistant Coatings for Zircaloy Cladings to Be Used in Nuclear Industry, KIT Internal Report, Karlsruhe Institute of Technology, Institute for Applied Materials, 2015.

[14] B.K. Choi, Y.-I. jung, H.G. Kim, I.H. Kim, Y.-H. Koo, D.J. Park, J.-Y. Park, Zirconium Alloy with Coating Layer Containing Very High Temperature Oxidation Resistant Material Such as Y2O3, Si02, ZrO2, Cr2O3, Al2O3, Cr3C2, SiC, ZrC,ZrN, Si and Cr, Brevet Coreen 2012KR-0067865, 25/06/2012.

[15] I. Idarraga-Trujillo, M. Le Flem, J.C. Brachet, M. Le Saux, D. Hamon, S. Muller, V. Vandenberghe, M. Tupin, E. Papin, E. Monsifrot, A. Billard, F. Schuster Assessment at CEA of Coated Nuclear Fuel Cladding for LWRS with Increased Margins in LOCA and beyond LOCA Conditions, TopFuel 2013, Charlotte, North Carolina, USA, September 15-19, 2013.

[16] J.C. Brachet, C. Lorrette, A. Michaux, C. Sauder, I. Idarraga-Trujillo, M. Le Saux M. Le Flem, F. Schuster, A. Billard, E. Monsifrot, E. Torres, F. Rebillat, J. Bischoff, A. Ambard, CEA Studies on Advanced Nuclear Fuel Claddings for Enhanced Accident Tolerant LWRs Fuel (LOCA and beyond LOCA Conditions), Fontevraud 8-Contribution of Materials Investigations and Operating Experience to LWRs' Safety, Performance and ReliabilityFrance, Avignon, 2014, September $15-18$.

[17] J.C. Brachet, A. Billard, F. Shuster, M. Le Flem, I. Idarraga-Trujillo, M. Le Saux, F. Lomello, Gaines de combustible nucléaire, procédés de fabrication et utilisation contre l'oxydation, Brevet Français FR 3025929B, 23/09/2014.

[18] J.C. Brachet, M. Le Saux, T. Guilbert, S. Urvoy, E. Rouesne, M. Le Flem, I. Idarraga-Trujillo, F. Schuster, F. Lomello, Chromium Coated Nuclear Fuel Claddings for Enhanced Accident Tolerant LWRs Fuel (DBA-LOCA and Slightly beyond DBA-LOCA Conditions), IAEA Technical Meeting on "Accident Tolerant Fuel Concepts for LWRs”, Oak Ridge National Laboratory, TN, USA, October 1317, 2014.

[19] J.C. Brachet, M. Le Saux, M. Le Flem, S. Urvoy, E. Rouesne, T. Guilbert, C. Cobac, F. Lahogue, J. Rousselot, M. Tupin, P. Billaud, C. Hossepied, F. Schuster, F. Lomello, A. Billard, G. Velisa, E. Monsifrot, J. Bischoff, A. Ambard, On Going Studies at CEA on Chromium Coated Zirconium Based Nuclear Fuel Claddings for Enhanced Accident Tolerant LWR's Fuel, Topfuel 2015, Zurich, Switzerland, 2015 Sept. 13-17.

[20] A.S. Kuprin, V.A. Belous, V.N. Voyevodin, V.V. Bryk, R.L. Vasilenko V.D. Ovcharenko, E.N. Reshetnyak, G.N. Tolmachova, P.N. Vyugov, Vacuum-arc chromium-based coatings for protection of zirconium alloys from the hightemperature oxidation in air, J. Nucl. Mater. 465 (2015) 400-406.

[21] Hyun-Gil Kim, Il-Hyun Kim, Yang-Il Jung, Dong-Jun Park, Jeong-Yong Park Yang-Hyun Koo, Adhesion property and high-temperature oxidation behavior of $\mathrm{Cr}$ coated Zircaloy-4 cladding tube prepared by 3D laser coating, J. Nucl. Mater. 465 (2015) 531-539.

[22] V.V. Bryk, V.N. Voyevodin, I.M. Neklyudov, A.N. Rakitskij, Microstructure 
investigation of $\mathrm{Cr}$ and $\mathrm{Cr}$ alloys irradiated with heavy ions, J. Nucl. Mater. 225 (1995) 146-153.

[23] M. Biget, F. Maury, P. Vajda, A. Lucasson, P. Lucasson, Atomic displacement in low temperature irradiated chromium crystals, J. Phys. 40 (1979) 293-298.

[24] C.W. Weaver, Irradiation and the ductility of chromium, Scripta Metall. 2 (1968) 463-466.

[25] V. Chakin, V. Kazakov, Yu Goncharenko, Z. Ostrovsky, Formation of the aphase in Cr-Fe alloys under irradiation, J. Nucl. Mater. 233-237 (1996) $573-576$.

[26] A. Jain, S. Loganathan, J.D. Kanjilal, G.K. Mehta, High energy heavy ion irradiation of chromium films, Vacuum 46 (1995) 369-371.

[27] W.Z. Li, H. Kheurandish, Z. Al-Tamimi, W.A. Grant, $\mathrm{Cr}^{+}$ion irradiation and thermal annealing of chromium films on silicon for formation of silicides, Nucl. Inst. Meth. Phys. Res. 19 (20) (1987) 723-730.

[28] R. Nagar, B.R. Mehta, J.P. Singh, D. Jain, V. Ganesan, S.V. Kesapragada, D. Gall, Effect of swift heavy ion irradiation on the hardness of chromium nanorods J. Vac. Sci. Technol. 26 (887) (2008) 887-892.

[29] N. Kuratani, A. Ebe, K. Ogata, I. Shimizu, Y. Setsuhara, S. Miyake, Fundamental study of ion irradiated effects on the columnar growth of chromium films prepared by ion-beam and vapor deposition, J. Vac. Sci. Technol. 153 (2001) $153-155$.

[30] R. Van Nieuwenhove, J. Balak, A. Toivonen, S. Pentiila, U. Ehrnstern, Investigation of coatings ,applied by PVD, for the corrosion protection of materials in supercritical water, Conference paper, ISSCWR6-13024, 2013.

[31] R. Van Nieuwenhove, IFA-774: the First In-pile Test with Coated Fuel Rods, 2015 Feb. 03.

[32] R. Van Nieuwenhove, OECD Halden Reactor Project, IFA-774: the First In-pile Test with Coated Fuel Rods, 2014 Mar. 18.

[33] J. Ribis, A. Wu, J.C. Brachet, C. Toffolon-Masclet, F. Barcelo, B. Arnal, Atomicscale Interface Structure of $\mathrm{Cr}$-coated Zircalloy-4 Alloy - to Be Published.

[34] S. Pellegrino, P. Trocellier, S. Miro, Y. Serruys, E. Bordas, H. Martin, N. Chaâbane, S. Vaubaillon, J.P. Gallien, L. Beck, The JANNUS Saclay facility: a new platform for materials irradiation, implantation and ion beam analysis, Nucl. Instrum. Meth. Phys. Res. B 273 (2012) 213.

[35] R.E. Stoller, M.B. Toloczko, G.S. Was, A.G. Certain, S. Dwarraknath, F.A. Garner, On the use of SRIM for computing radiation damage exposure, Nucl. Instrum. Meth. Phys. Res. B 310 (2013) 75-80.

[36] X.-Q. Chen, W. Wolf, R. Podloucky, P. Rogl, Ab initio study of ground state properties of the Laves phases compounds $\mathrm{TiCr}_{2}, \mathrm{ZrCr}_{2}$ and $\mathrm{HfCr}_{2}$, Phys. Rev. B 71 (2005).

[37] V.N. Shishov, et al., Influence of neutron irradiation on dislocation structure and phase composition of $\mathrm{Zr}$-Base alloys, Zirconium in the nuclear industry, in: 11th Symposium, 1996, pp. 603-620.

[38] J.J. Kai, W.I. Huang, H.Y. Chou, The microstructural evolution of zircaloy-4 subjected to proton irradiation, J. Nucl. Mater. 170 (1990) 193-209.

[39] N.A. Dubrovinskaia, L.S. Dubrovinsky, S.K. Saxcna, B. Sundman, Thermal expansion of chromium (Cr) to melting temperature, Calphad 21 (4) (1997) 497-508.

[40] Z. Erdelyi, M. Sladecek, L.-M. Stadler, I. Zizak, G.A. Langer, M. Kis-Varga, D.L. Beke, B. Sepiol, Transient interface sharpening in miscible alloys, Science 306 (2004) 1913-1915.

[41] H. Wan, Y. Shen, X. Jin, Y. Chen, J. Sun, Effects of coherency stress and vacancy sources/sinkson interdiffusion across coherent multilayer interfaces - Part II: interface sharpening and intermixing rate, Acta Mater. 60 (2012) 2539-2553.

[42] Z. Erdelyi, D.L. Beke, Stress effects on diffusional interface sharpening in idea binary alloys, Phy.l Rev. B 68 (2003), 092102

[43] A.P. Ehiasarian, J.G. Wen, I. Petrov, Interface microstructure engineering by high power impulse magnetron sputtering for the enhancement of adhesion, J. Appl. Phys. 101 (2007), 054301.

[44] S.A. Dregria, P. Wynblatt, Equilibrium segregation and interfacial energy in multicomponent systems, Acta Metall. Mater. 39 (5) (1991) 71-778.

[45] W. Xiang, S. Ying, Reaction Diffusion in Chromium-Zircaloy-2 System, China Nuclear Science and Technology Report, 2001.

[46] G. Vogl, M. Sugimoto, Y. Yoshida, High-temperature observations of the dynamics of small second phase particles leading to fast diffusion of iron in $\alpha-$ zirconium, J. Nucl. Mater. 199 (1993) 112-120.

[47] C.-S. Zhang, B. Li, P.R. Norton, The segregation of Fe to a zirconium surface, J. Nucl. Mater. 223 (1995) 238-244.

[48] C.-S. Zhang, B. Li, P.R. Norton, The segregation of Fe on the (1010) Zr surface, Surf. Sci. 338 (1995) 157-168.

[49] R.A. Perez, H. Nakajima, F. Dyment, Diffusion in $\alpha$-Ti and Zr, Mater. Trans. 44 (1) (2003) 2-13.

[50] A.D. King, G.M. Hood, R.A. Holt, Fe-enhancement of self-diffusion in $\alpha$-Zr, J. Nucl. Mater. 185 (1991) 174-181.

[51] C. Toffolon-Masclet, J.-C. Brachet, G. Jago, Studies of second phase particles in different zirconium alloys using extractive carbon replica and an electrolytic anodic dissolution procedure, J. Nucl. Mater. 305 (2002) 224-231.

[52] R.A. Versaci, M. Ipohorski, Polytype structure of intermetallic precipitates in Zircaloy-4 alloys, J. Nucl. Mater. 80 (1979) 180-183.

[53] J.B. Vander Sande, A.L. Bement, An investigation of second phase particles in Zircaloy-4 alloys, J. Nucl. Mater. s 52 (1974) 115-118.

[54] R.A. Versaci, M. Ipohorski, Composition of $\mathrm{Zr}(\mathrm{Fe}, \mathrm{Cr})_{2}$-type precipitates in Zircaloy-2 and Zircaloy-4, J. Nucl. Mater. 116 (1983) 321-323.

[55] W.J.S. Yang, R.P. Tucker, B. Cheng, R.B. Adamson, Precipitates in Zircaloy: identification and the effect of irradiation and thermal treatment, J. Nucl. Mater. 138 (1986) 185-195.

[56] N. Dupin, I. Ansara, C. Servant, C. Toffolon, C. Lemaignan, J.C. Brachet, A thermodynamic database for zirconium alloys, J. Nucl. Mater. (1999) 287-295.

[57] M. Griffiths, R.W. Gilbert, G.J.C. Carpenter, Phase instability, decomposition and redistribution of intermetallic precipitates in Zircaloy-2 ans -4 during neutron irradiation, J. Nucl. Mater. 150 (1987) 53-66.

[58] Y. Idrees, Z. Yao, M.A. Kirk, M.R. Daymond, In situ study of defect accumulation in zirconium under heavy ion irradiation, J. Nucl. Mater. 433 (2013) 95-107.

[59] L.M. Howe, D. Phillips, A.T. Motta, P.R. Okamoto, Irradiation-induced phase transformations in zirconium alloys, Surf. Coating. Technol. 66 (1994) $411-418$.

[60] F. Lefebvre, C. Lemaignan, Heavy ion-induced amorphisation of $\mathrm{Zr}(\mathrm{Fe}, \mathrm{Cr})_{2}$ precipitates in Zircaloy-4, J. Nucl. Mater. 165 (1989) 122-127.

[61] A. Arranz, Influence of the ion type on the ion beam mixing of $\mathrm{Cr} / \mathrm{Al}$ interfaces, Appl. Surf. Sci. 258 (2012) 3264-3268.

[62] Y.-T. Cheng, M. Van Rossum, M.-A. Nicolet, W.L. Johnson, Influence of chemical driving forces in ion mixing of metallic bilayers, Appl. Phys. Lett. 45 (1984) 185.

[63] M. Milosavljevic, N. Stojanovi, D. Perusko, B. Timotijevi, D. Toprek, J. Kovac, G. Drazic, C. Jeynes, Ion irradiation induced $\mathrm{Al}-\mathrm{Ti}$ interaction in nano-scaled Al/Ti multilayers, Appl. Surf. Sci. 258 (2012) 2043-2046.

[64] W. Bolse, Mechanisms of ion beam induced atomic mixing in solids, Mater. Sci. Eng. 253 (1998) 194-201. 